\title{
Model Sistem Informasi Biaya Kunjungan Wisata di Provinsi Sulawesi Utara
}

\author{
Yonatan Parassa $^{1 *}$, Mex U. Pesik ${ }^{2 * *}$, Nathaniel L. Bijang ${ }^{3 *}$ \\ * Teknik Informatika, Politeknik Negeri Manado \\ ** Pariwisata, Politeknik Negeri Manado \\ *** Tekik Elektro, Politeknik Negeri Manado \\ yonatan.pa@gmail.com ${ }^{1}, \underline{\text { mex.pesik.18@gmail.com }}^{2}$, bijangnathaniel@gmail.com $^{3}$
}

\begin{tabular}{l} 
Article Info \\
\hline Article history: \\
Received : 08-11-2018 \\
Revised : 18-11-2018 \\
Accepted : 04-11-2018 \\
\hline
\end{tabular}

Keyword:

Cost of tourist visit, System model,

Tourist.

\begin{abstract}
Cost is one of the important information needed by tourists and prospective tourists in planning and conducting tourist visits. This study aims to produce a system model that can record, process, and present information about the cost picture when tourists or potential tourists to travel in North Sulawesi province such as overview of accommodation costs, transportation, culinary and cost of tourist attraction. Using waterfall method in system development. Data collection by observation, interview and literature. Testing system using blackbox method. The result of this research is a system model that can present information about the cost picture starting from the description of minimum cost and others which make the information need of the cost can be fulfilled, so it is expected to help the tourist in traveling and support the tourism industry in North Sulawesi Province.
\end{abstract}

\section{Pendahuluan}

Perkembangan teknologi dewasa ini sangat pesat, hampir semua sisi kehidupan telah disentuh oleh teknologi, hal ini untuk mempermudah kehidupan manusia termasuk dalam hal pengolahan data.Implementasi teknologi komputer sebagai perangkat untuk membantu pengolahan data sudah merupakan hal yang lazim. Hampir semua bidang ditemukan perangkat komputer untuk membantu pengolahan data. Seperti di supermarket, dunia perbankan, termasuk di kantor-kantor baik itu perkantoran swasta maupun intitusi pemerintah.

Pariwisata adalah suatu perjalanan yang dilakukan untuk sementara waktu, yang diselenggarakan dari suatu tempat ke tempat lain, dengan maksud bukan untuk berusaha (business) atau mencari nafkah di tempat yang dikunjungi, tetapi semata-mata untuk memenuhi keinginan yang beraneka ragam [1].

Perjalanan wisata yang direncanakan oleh kalangan masyarakat di manapun, termasuk oleh kelompok masyarakat lapisan bawah terutama di negara-negara maju perlu memperhitungkan banyak faktor. Sebab berwisata landasannya adalah kegiatan berlibur dengan memerlukan biaya. Jika seseorang atau sekelompok orang berpenghasilan pas-pasan, tidak bisa menabung, informasi wisata terbatas dan seterusnya; maka mereka tidak mungkin merencanakan berwisata atau perjalanan wisata. Jadi, berwisata memerlukan biaya besar yang harus dikeluarkan dari sumber penghasilan ekstra atau di luar kebutuhan pokok [2].

Dari sisi wisatawan atau pengunjung, informasi dibutuhkan untuk merencanakan perjalanan dari tempat tinggal atau asal hingga ke tempat tujuan, selama berada di sana hingga kembali ke tempat asal atau tempat tinggal. Selain agar mendapatkan gambaran yang jelas mengenai keadaan tempat yang akan dikunjungi, wisatawan juga dapat menyiapkan dana atau anggaran yang sesuai untuk perjalanan agar tidak terjadi hal-hal yang tidak diinginkan sehingga perjalanan itu benar-benar dapat menyenangkan sesuai dengan tujuan perjalanan. Informasi tersebut antara lain menyangkut alat transportasi, akomodasi dan obyek wisata [3].

Besaran biaya adalah suatu kebutuhan untuk dapat melakukan perjalanan wisata. Sistem yang dapat menyajikan kebutuhan gambaran biaya berupa biaya transportasi, akomodasi, makanan di suatu daerah akan sangat bermanfaat bagi wisatawan untuk melakukan perjalanan khususnya di Provinsi Sulawesi Utara. 
Artikel ini membahas mengenai bagaimana membuat model sistem informasi biaya perjalanan wisata di Provinsi Sulawesi Utara. Tujuan dari penelitian ini adalah untuk menghasilkan model sistem yang dapat menyajikan informasi mengenai gambaran biaya ketika melakukan perjalanan wisata. Hasil dari penelitian ini adalah menghasilkan model sistem informasi yang dapat merekam, memproses dan menyajikan informasi mengenai gambaran biaya ketika melakukan perjalanan di Provinsi Sulawesi Utara.

\section{Metode Panelitian}

Metode pengambilan data menggunakan metode observasi, wawancara dan juga studi pustaka. Metode pengembangan sistem menggunakan metode waterfall seperti pada gambar berikut [4], yang disesuaikan dengan kebutuhan sistem, yaitu model sistem informasi biaya wisata di Provinsi Sulawesi Utara:

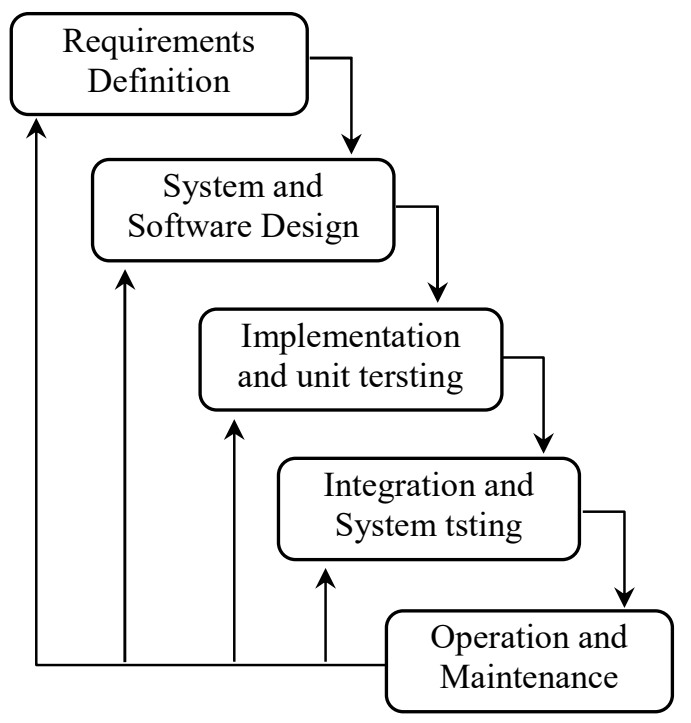

Gambar 1. Metode Waterfall

Metode pengembangan sistem menggunakan metode waterfall terdiri dari beberapa tahapan, yaitu:

1) Requirement Analysis and Definition

Requirement Analysis and Definition adalah tahapan penetapan fitur, kendala dan tujuan sistem melalui konsultasi dengan pengguna sistem. Semua hal tersebut akan ditetapkan secara rinci dan berfungsi sebagai spesifikasi system.

\section{2) System and Software Design}

Pada Tahap System and Software Design ini akan dibentuk suatu arsitektur sistem berdasarkan persyaratan yang telah ditetapkan. Selain itu juga, dilakukan identifikasi dan penggambaran terhadap abstraksi dasar sistem perangkat lunak beserta hubungan-hubungannya.
3) Implementation and Unit Testing

Dalam tahapan Implementation and Unit Testing ini, hasil dari desain perangkat lunak akan direalisasikan sebagai satu set program atau unit program. Setiap unit akan diuji apakah sudah memenuhi spesifikasinya.

4) Integration and System Testing

Dalam tahap Integration and System Testing ini, setiap unit program akan diintegrasikan satu sama lain dan diuji sebagai satu sistem yang utuh untuk memastikan sistem sudah memenuhi persyaratan yang ada. Setelah itu sistem akan dikirim ke pengguna sistem.

5) Operation and Maintenance

Dalam tahap Operation and Maintenance ini, sistem diinstal dan mulai digunakan. Selain itu juga memperbaiki error yang tidak ditemukan pada tahap pembuatan. Dalam tahap ini juga dilakukan pengembangan sistem seperti penambahan fitur dan fungsi baru. Penelitian ini menggunakan waterfall sesuai dengan kebutuhan sistem.

\section{HASIL DAN PEMBAHASAN}

\section{A. Requirement Analysis and Definition}

Tujuan model sistem ditetapkan dengan menggunakan teknik wawancara kepada pengguna sistem dalam hal ini pegawai di Dinas Pariwisata dan Pengguna Internet, dan juga melalui studi pustaka.

Dari data yang diperoleh, Informasi biaya wisata yang paling dibutuhkan adalah biaya transportasi, biaya akomodasi dan biaya makan minum. Model sistem informasi biaya wisata harus mampu menyajikan gambaran data dan informasi di daerah Provinsi Sulawesi Utara.

\section{B. Perancangan Sistem}

Perancangan sistem menggunakan beberapaka teknik dan perangkat perancangan, yaitu:

1. Menggunakan Entity Relationalship (ER) Diagram untuk perancangan database

ER memungkinkan kita menggambaran data dalam konteks objek dan hubungannya, dan digunakan secara luas untuk mengembangkan desain database awal. Diagram ER hanyalah deskripsi perkiraan mengenai data, disusun melalui evaluasi subjektif terhadap informasi yang dikumpulkan selama analisis persyaratan [5]. Rancangan ER seperti pada gambar berikut: 


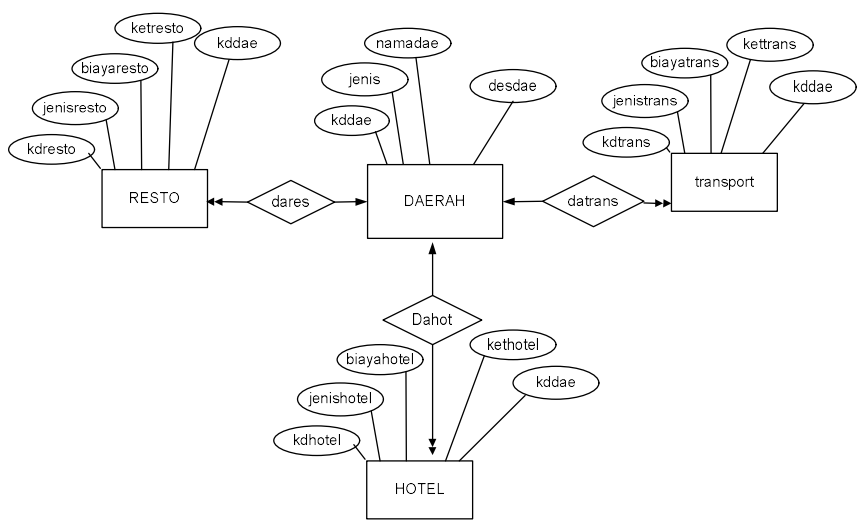

Gambar 2. Rancangan ER

\section{Diagram Konteks}

Diagram Konteks adalah diagram yang menggambarkan sumber serta tujuan data yang akan diproses atau dengan kata lain diagram tersebut digunakan untuk menggambarkan sistem secara umum/global dari keseluruhan sistem yang ada [6]. Berikut adalah diagram konteks yang digunakan:

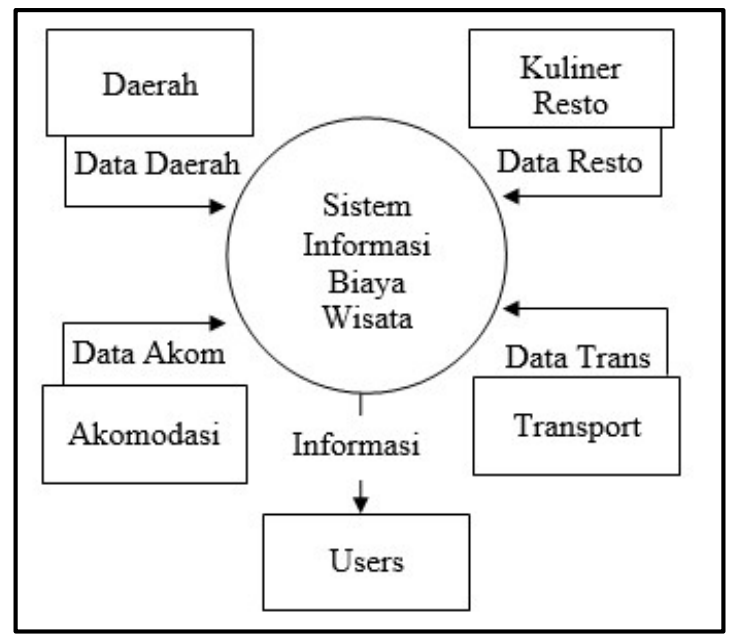

Gambar 3. Diagram Konteks

\section{Implementasi dan Pengujian}

Dari tahapan perancangan, maka tahapan selanjutnya adalah implementasi dan pengujian, sehingga nantinya dapat diketahui perancangan sudah berjalan sesuai dengan kebutuhan. Berdasarkan analisis ditetapkan tujuan dari sistem adalah model sistem yang dapat menyajikan informasi gambaran biaya wisata di Provinsi Sulawesi Utara, dengan titik acuan wisatawan berada di daerah Manado. Laporan biaya wisata untuk komponen biaya penginapan dapat dilihat seperti pada gambar berikut:

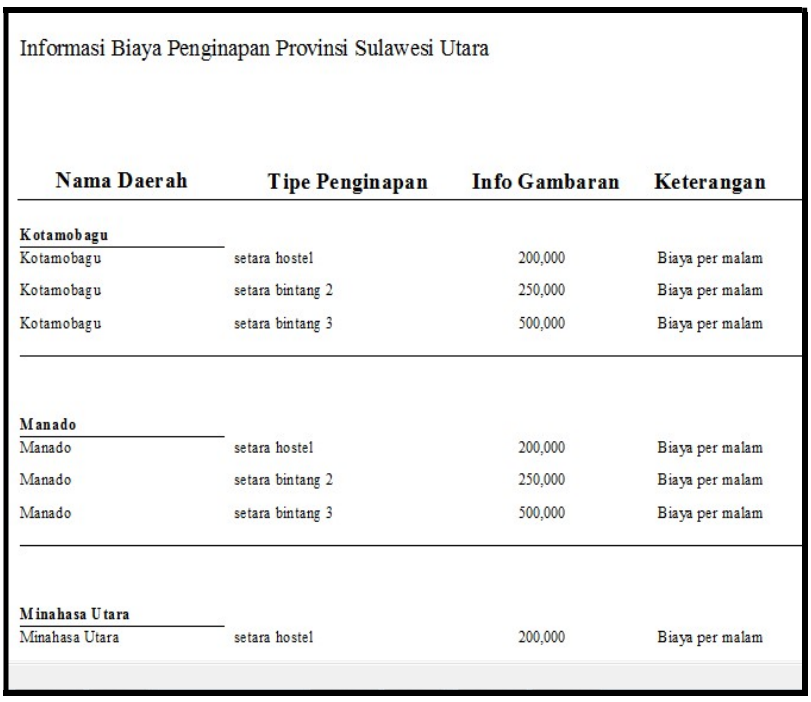

Gambar 4. Gambaran Biaya Penginapan

Sistem juga mampu menyajikan report mengenai gambaran biaya penginapan, transportasi dan makanan / kuliner seperti pada gambar berikut:

\begin{tabular}{|c|c|c|c|c|}
\hline \multicolumn{5}{|c|}{ INFORMASI BIAYA PARIWISAT A SULAWESI UTARA } \\
\hline Nama Daerah & Komponen & Tipe & Biaya & Keterangan \\
\hline Kotamobagu & hotel & & & \\
\hline Kotamobagu & hotel & setara hostel & 200,000 & Biaya per malam \\
\hline Kotamobagu & hotel & $\begin{array}{l}\text { setara } \\
\text { bintang } 3\end{array}$ & 500,000 & Biaya per malam \\
\hline Kotamobagu & hotel & $\begin{array}{l}\text { setata } \\
\text { bintang } 2\end{array}$ & 250,000 & Biaya per malam \\
\hline Kotamobagu & resto & & & \\
\hline Kotamobagu & $\frac{T e s t o}{\text { resto }}$ & $\begin{array}{l}\text { Makanan } \\
\text { setara resto }\end{array}$ & 70,000 & paket nasi \\
\hline Kotamobagu & resto & Minuman & 35,000 & jenis jus \\
\hline Kotamobagu & resto & $\begin{array}{l}\text { Makanan } \\
\text { setara resto } \\
\text { family }\end{array}$ & 35,000 & paket nasi \\
\hline Kotamobagu & resto & $\begin{array}{l}\text { Minuman } \\
\text { setara resto } \\
\text { family }\end{array}$ & 20,000 & jenis jus \\
\hline Kotamobagu & resto & Makanan & 17,000 & paket nasi \\
\hline
\end{tabular}

Gambar 5. Info biaya Penginapan, Transport dan Kuliner

Pengujian sistem menggunakan metode black box, yang disebut juga functional testing, sebuah teknik pengujian fungsional yang merancang test case berdasarkan informasi dari spesifikasi [7]. Black box testing juga disebut pengujian tingkah laku, memusat pada kebutuhan fungsional perangkat lunak. Teknik pengujian black box memungkinkan memperoleh serangkaian kondisi masukan yang sepenuhnya menggunakan semua persyaratan fungsional untuk suatu program. Beberapa jenis kesalahan yang dapat diidentifikasi adalah fungsi tidak benar atau hilang, kesalahan antar muka, kesalahan pada struktur data (pengaksesan basis data), kesalahan performasi, kesalahan inisialisasi dan akhir program. [8]. Pengujian model sistem informasi biaya wisata di Propinsi Sulawesi Utara telah 
dilakukan dan memenuhi persyaratan, diantaranya terlihat dari berbagai report yang mampu dihasilkan oleh sistem.

\section{KESIMPULAN}

Berdasarkan tahapan dalam penelitian ini kesimpulan yang diperoleh dari penelitian ini adalah model sistem informasi biaya kunjungan wisata di Provinsi Sulawesi Utara yang dibangun dengan menggunakan metode waterfall yang disesuaikan dengan kebutuhan sistem telah memenuhi definisi kebutuhan, dimana telah melalui beberapa tahapan dari tahap penetapan kebutuhan sistem, tahapan perancangan dan pengujian sistem, dimana seluruh fungsionalitas sistem telah diuji. Sistem mampu menghasilkan laporan-laporan mengenai gambaran biaya wisata yang paling dibutuhkan yaitu penginapan, transport dan makanan di daerah Provinsi Sulawesi Utara. Model sistem informasi biaya wisata di Provinsi Sulawesi Utara dapat dikembangkan untuk diimplementasikan secara daring, sehingga pengguna dapat langsung mengakses informasi gambaran biaya wisata di Provinsi Sulawesi Utara.

\section{UCAPAN TERIMA KASIH}

Terimakasih kepada Pemerintah Negara Republik Indonesia dalam hal ini Kementerian Riset, Teknologi dan
Pendidikan Tinggi yang telah mendanai penelitian ini melalui Direkorat Riset dan Pengabdian kepada Masyarakat. Penulis juga menghaturkan terimakasih kepada Pimpinan Politeknik Negeri Manado, Lembaga Penelitian dan Pengabdian kepada Masyarakat Polititeknik Negeri Manado, Rekan Kerja di Politeknik Negeri Manado, dan semua pihak yang terlibat dalam penelitian ini. Semoga Tuhan terus menolong dan memberkati kita semua.

\section{DAFTAR PUSTAKA}

[1] A.Yoeti, Oka. 1996. "Pengantar Ilmu Pariwisata". Angkasa: Bandung

[2] Soemanto, R. B. (2010). "Sosiologi Pariwisata".

[3] Manongga, D., Papilaya, S., \& Pandie, S. (2010). "Sistem Informasi Geografis Untuk Perjalanan Wisata Di Kota Semarang”. Jurnal Informatika, 10(1), 1-9.

[4] Sommerville, Ian. 2011. "Software Engineering (Rekayasa Perangkat Lunak).” Erlangga, Jakarta.

[5] Raghu, R., \& Gehrke, J. (2004). "Sistem Manajemen Database Edisi 3". Andi Publisher. Jakarta.

[6] Jogiyanto, 2010. "Analisis dan Desain Sistem Informasi, Edisi IV", Andi Offset, Yogyakarta.

[7] Nidhra, Srinivas dan Jagruthi Dondeti. 2012." Black box and White box Testing Techniques - A Literature Review". Internasional Journal of Embedded System and Applications (IJESA) Vol.2, No.2

[8] Pressman, Ph.D. Roger S. 2010. Pendekatan Praktisi Rekayasa Perangkat Lunak. Edisi 7. Andi. Yogyakarta 